\title{
TRABALHANDO A EDUCAÇÃO AMBIENTAL A PARTIR DA PROBLEMÁTICA SÓCIO-AMBIENTAL DE UMA LAGOA COSTEIRA
}

\author{
Marcelo Silveira, Marina Ferreira Campos Pinto \\ Acadêmicos do Curso de Ciências Biológicas da UFSC \\ Dra. Vera Lícia Vaz de Arruda \\ Professora do Departamento de Ecologia e Zoologia da UFSC (Coordenadora) \\ vera_licia@yahoo.com.br
}

\section{Resumo}

O objetivo deste artigo é relatar o trabalho de educação ambiental realizado com duas turmas de uma escola pública de Florianópolis, SC, a partir de questões sócio-ambientais geradas pelos problemas enfrentados por uma lagoa costeira. De junho a dezembro de 2006, foram realizadas saída de campo para a lagoa, construção de maquete de argila e dinâmicas em sala com cada turma. Com essas atividades, os alunos puderam refletir sobre os problemas da lagoa e propor soluções para eles.

Palavras-chave: Educação ambiental. Escola. Lagoa costeira.

\section{DEVELOPING ENVIRONMENTAL EDUCATION BASED ON AN URBAN COASTAL LAGOON SOCIO-ENVIRONMENTAL PROBLEMATICS}

\begin{abstract}
The aim of this study was the development of environmental education activities focused on two public school classes at Florianópolis, SC, such activities were based on socioenvironmental issues related to an urban coastal lagoon. Field trips, the built of a clay mockup and classroom dynamics were conducted from June to December 2006. Students were able to reflect about the problems and they also tried to suggest solutions.
\end{abstract}

Keywords: Environmental education. School. Coastal lagoon. 


\section{Introdução}

A Lagoa da Chica localiza-se em uma importante formação geológica, na Planície Costeira, mais especificamente na Planície do Campeche, localizada ao sul da Ilha de Santa Catarina. A porção mais externa da Planície Costeira é representada por cordões de dunas fixas ou semifixas, e logo atrás destes cordões, encontra-se uma extensa área de restinga. A Planície do Campeche é caracterizada por ser rica em ambientes inundáveis, devido ao fato do solo da região apresentar composição arenosa, o que facilita a drenagem e filtração das águas provenientes das chuvas. Quando filtradas pelo solo, as águas se juntam ao lençol freático da Planície do Campeche, que é de grande importância para o abastecimento hídrico da região. O afloramento deste lençol subjacente forma lagoas encontradas na região, que podem ser intermitentes ou sazonais, e variam seu leito conforme a saturação do lençol. As duas principais lagoas formadas por afloramento são a Lagoa Pequena e a Lagoa da Chica (BARBOSA, 1999; MCQV, 2000).

A lagoa da Chica é uma Área de Preservação Permanente (APP) que abrange um território de 4,6 hectares e foi tombada como patrimônio Natural e Paisagístico do Município de Florianópolis pelo decreto municipal $n^{\circ} 135 / 88$, de 5 de junho de 1988 . Com intuito de proteger o entorno da Lagoa, é garantida também uma faixa ao seu redor de 50 metros medidos a partir do seu leito maior sazonal, demarcado na época da elaboração do decreto (FLORAM, [s.d.]). No entanto, esta área sofre com fortes problemas de ocupação e loteamentos ilegais ao seu redor que podem comprometer a qualidade da água por causa de suas fossas. Além disso, existem canais de drenagem que prejudicam o abastecimento do manancial (CECCA, 1997).

Devido à omissão da administração pública em relação à área da lagoa, ela se encontra abandonada, e está se transformando em depósito de lixo e entulhos. Amora (1996) menciona que a ocupação da área em torno da Lagoa da Chica começou em 1970 e no início se deu lentamente. A partir de meados dos anos 80, a invasão da área para construção de residências se agravou.

Entre junho e dezembro de 2006, foi desenvolvido um projeto, financiado pelo Departamento de Apoio à Extensão (DAEx), que a partir de 2008, passou a chamar-se Departamento de Projetos de Extensão (DPE) da Universidade Federal de Santa Catarina (UFSC) com o título “A Lagoa da Chica como tema gerador de educação ambiental”. Nele foi realizado o levantamento da problemática da Lagoa da Chica e o encaminhamento de pedidos da comunidade à Fundação Municipal do Meio Ambiente de Florianópolis (FLORAM), órgão 
responsável pela área. Paralelamente a essas atividades, surgiu a necessidade de incluir a escola do bairro no projeto de Educação Ambiental para que houvesse maior envolvimento das crianças da comunidade com as questões ambientais relativas à lagoa.

Considera-se a educação ambiental uma educação política, reflexiva, crítica, formadora de cidadania, onde a ética, no sentido de respeito à vida, ocupa um papel fundamental. Segundo Reigota (1996), o conteúdo mais indicado para a educação ambiental deve ser originado do levantamento da problemática ambiental vivida cotidianamente pelos alunos e pela comunidade em geral, e que se queira resolver. Guimarães (1995) menciona que além de conhecimentos sobre o meio ambiente e os problemas que o afetam, a educação ambiental deve possibilitar a sensibilização à problemática ambiental, resgatando valores sociais como o respeito à vida, solidariedade, honestidade, responsabilidade, além de favorecer a participação ativa na resolução dos problemas ambientais.

A questão ambiental está interligada às dimensões sócio-econômica, política, cultural, histórica, ética e estética. A educação ambiental, ao priorizar a abordagem interdisciplinar (GUIMARÃES, 2000; REIGOTA, 1996) facilita a compreensão dessa realidade complexa. A interdisciplinaridade favorece a abertura de um espaço de mediação entre conhecimentos e a articulação de saberes e necessita de troca, diálogo, aceitar o pensar do outro (CARVALHO, 2004; FAZENDA, 1996).

O objetivo deste projeto foi realizar um trabalho de Educação Ambiental com crianças de uma escola da rede pública, através da problemática sócio-ambiental de uma lagoa costeira.

\section{Material e Métodos}

Foi realizado um estudo dos elementos da paisagem da Lagoa da Chica e de seus arredores nos últimos 50 anos. Este trabalho foi baseado em fotointerpretação de aerofotos obtidas junto ao Instituto de Planejamento Urbano de Florianópolis (IPUF) e em registros fotográficos obtidos com os moradores. Os conhecimentos produzidos através do estudo dos elementos da paisagem auxiliaram nas atividades realizadas com os alunos. As imagens resgatadas foram utilizadas por eles como ferramenta de ensino em alguns encontros, o que possibilitou trabalhar os aspectos históricos associados aos ecológicos e sociais.

As atividades foram desenvolvidas entre junho e dezembro de 2006, na Escola Municipal Brigadeiro Eduardo Gomes, bairro Campeche, município de Florianópolis, Santa Catarina, localizada a pouco mais de $1 \mathrm{~km}$ da Lagoa da Chica. Essa escola atende alunos de $1^{\mathrm{a}}$ 
a $8^{\text {a }}$ série. Foram realizadas reuniões de planejamento com a diretora, o coordenador e os professores, nas quais ficou estabelecido que as atividades seriam feitas com as turmas da $5^{\mathrm{a}} \mathrm{e}$ $8^{\mathrm{a}}$ séries, com seus respectivos professores Santiago (Geografia) e Renata (Ciências). As atividades foram as mesmas para cada turma, porém, separadas entre elas. Foram realizados cinco encontros com cada turma, que continha aproximadamente 25 crianças.

Encontro 1: a turma foi dividida em 4 equipes, cada uma recebeu uma questão relacionada às lagoas da Ilha de Santa Catarina, sobre a qual deveriam discutir. As questões distribuídas entre as equipes foram:

- evolução da Lagoa da Chica - estudo da paisagem da Lagoa da Chica e seus arredores nos últimos 50 anos;

- diferenças entre a Lagoa da Chica e a Lagoa Pequena ${ }^{1}$ - uma comparação entre as duas;

- diferenças entre a Lagoa da Chica e a Lagoa da Conceição ${ }^{2}$ - uma comparação entre as duas;

- fontes de poluição no Campeche - levantamento dos tipos de poluição encontrados no bairro.

Às equipes que trabalharam o tema Evolução da Lagoa da Chica, foram entregues fotografias aéreas conseguidas no IPUF, e a partir delas, tiraram suas conclusões sobre o processo ocorrido na lagoa. As demais equipes utilizaram seus próprios conhecimentos e experiências para discutir o tema mencionado acima. No final da aula, um aluno de cada equipe apresentou para a turma os resultados obtidos.

Encontro 2: a aula foi iniciada pedindo que cada aluno (reunido com o seu grupo da aula anterior) produzisse um texto sobre o tema trabalhado por sua equipe. Os alunos terminaram a atividade antes do encerramento da aula, assim, realizou-se a seguinte dinâmica com a turma: cada aluno recebeu uma palavra escrita em um papel e a grudou em si. A turma ficou em círculo, e cada aluno, segurando um barbante, tinha que procurar uma palavra com alguma relação com a sua, explicar a relação e levar o barbante até a outra pessoa, formando uma teia.

\footnotetext{
${ }^{1}$ A Lagoa Pequena, cuja superfície total (incluindo parte colmatada) é de aproximadamente $186.372 \mathrm{~m}^{2}$, representa o mais importante afloramento do lençol freático da Planície do Campeche e, do ponto de vista hidrogeológico, ela constitui uma sub-bacia hidrológica do aqǘfero mais importante da ilha de Santa Catarina (BARBOSA, 1999).

${ }^{2}$ A Lagoa da Conceição, na ilha de Santa Catarina, é na realidade uma laguna ligada ao mar pelo Canal da Barra da Lagoa. A forma alongada (13,5 km no sentido Norte/Sul), em paralelo à linha costeira, é irregular, e recortada por dunas e morros formando três porções distintas (BARBOSA, 2003).
} 
Encontro 3: a turma foi caminhando até a Lagoa da Chica com o objetivo de estimular a observação do ambiente do bairro. Chegando lá foi dividida em equipes. Cada grupo recebeu perguntas (ver Resultados e Análise) que foram respondidas, apresentadas para os outros e entregues no término da atividade, ainda na lagoa.

Encontro 4: neste dia, foi realizada uma atividade com argila. A turma, em equipes, recebeu a tarefa de fazer uma maquete, retratando a situação da lagoa em diferentes épocas: a lagoa ontem, a lagoa hoje ou a lagoa amanhã. As diferentes situações a serem representadas foram entregues aleatoriamente aos grupos. Para aqueles que representaram o passado, foram entregues fotos da Lagoa da Chica das décadas de 80 e 90, obtidas com moradores dos arredores.

As maquetes com argila foram expostas no dia de apresentação dos trabalhos feitos durante o ano, para os pais e para a comunidade.

Encontro 5: como encerramento das atividades com a escola, após uma conversa sobre o futuro da lagoa, pediu-se que os alunos elaborassem um texto sobre o que eles achavam que deveria ser feito pelo futuro da lagoa.

Durante o desenvolvimento do projeto, algumas dificuldades foram encontradas na aplicação do método previsto. A proposta inicial era trabalhar a educação ambiental de forma interdisciplinar, envolvendo os professores de Ciências, Geografia, História, Artes, Português, Matemática, Educação Física da mesma turma em um tema comum (Lagoa da Chica). Isto não aconteceu como o esperado. Inicialmente foram reunidos professores de quatro áreas distintas, porém, a comunicação entre eles foi se perdendo aos poucos. Somente dois professores, um de cada área, responsáveis por turmas diferentes, acabaram participando das atividades.

A abordagem interdisciplinar começa a encontrar dificuldades no momento do planejamento. As pessoas envolvidas necessitam dispor de tempo em comum, e estarem motivadas para o planejamento conjunto das atividades, o que pressupõe flexibilidade dos docentes. Concorda-se com Fazenda (1996, p. 17) quando menciona que "um projeto interdisciplinar de trabalho ou de ensino precisa ser um projeto que não se oriente apenas para o produzir, mas que surja espontaneamente, no suceder diário da vida, de um ato de vontade”.

Outros aspectos que dificultaram o andamento das atividades foram a rotatividade e os afastamentos dos professores por licença-saúde e o esquecimento das datas marcadas para algumas atividades pelos professores envolvidos. 


\section{Resultados e Análise}

Estudo dos elementos da paisagem

O estudo dos elementos da paisagem da Lagoa da Chica e seus arredores nos últimos 50 anos foi baseado nas fotos aéreas de 1957, 1977, 1994, 1998, 2001 e 2002 (Figura 1).

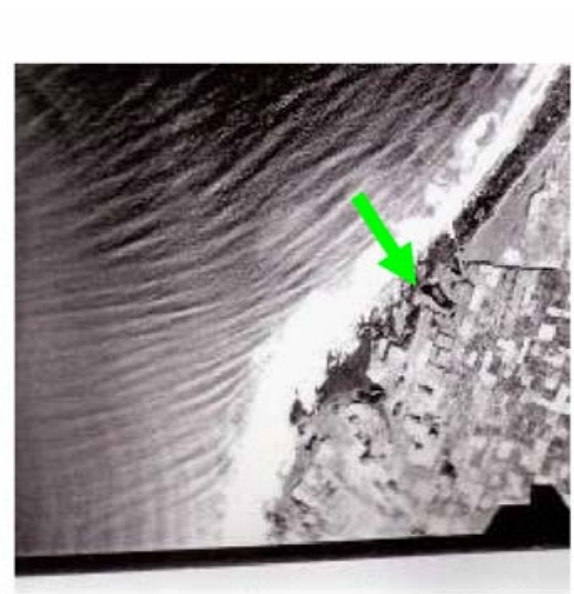

a

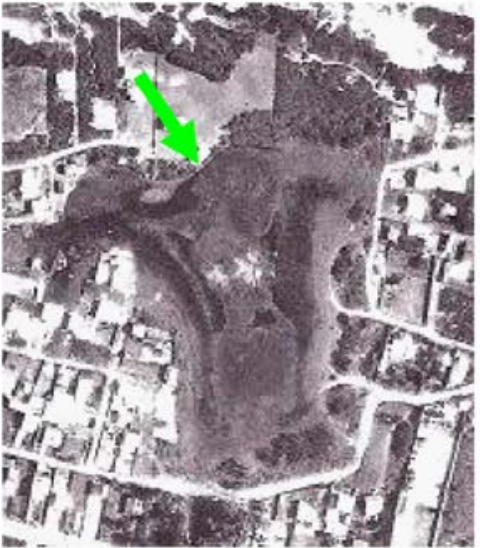

c

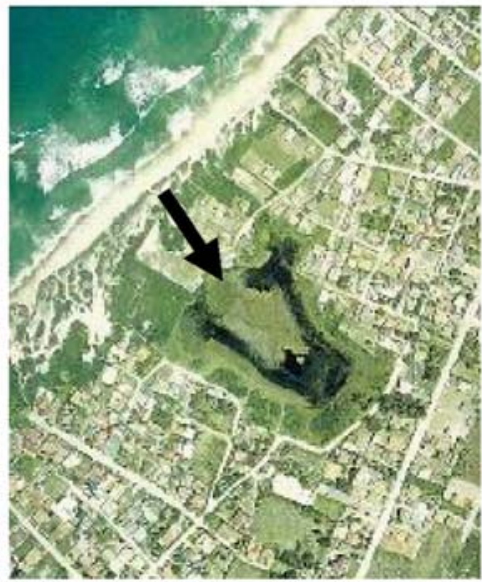

e

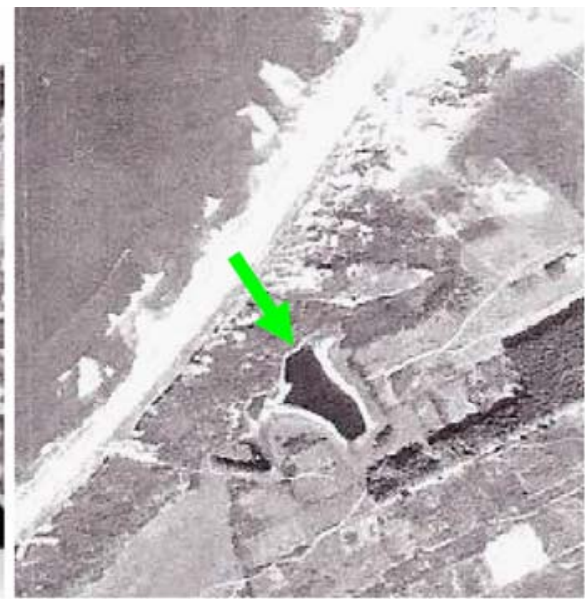

$\mathrm{b}$
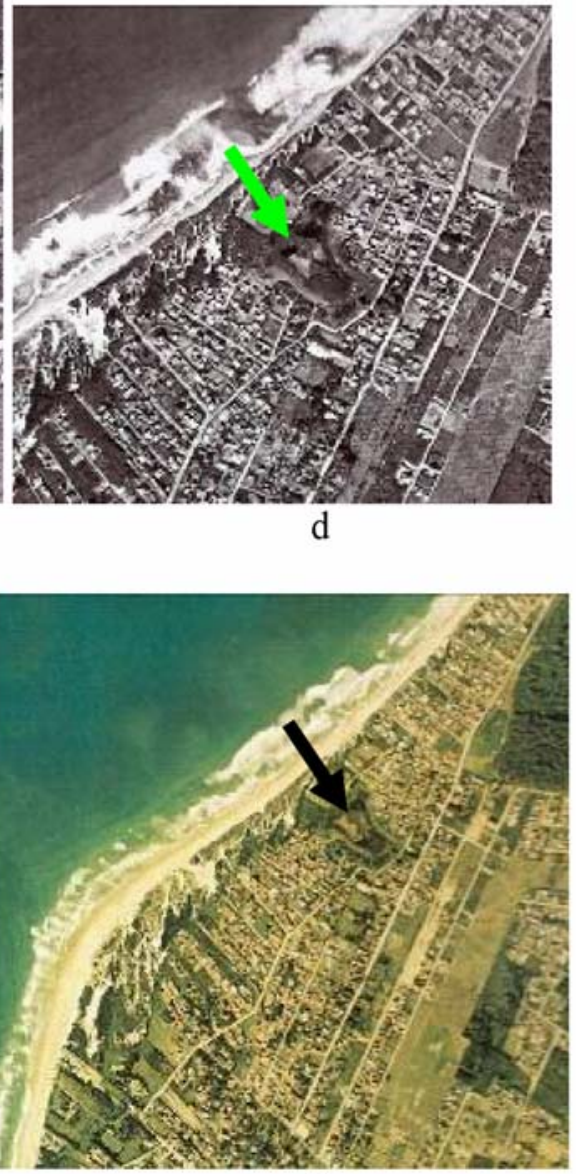

f

Figura 1: Fotos aéreas da Lagoa da Chica (apontada pela seta) e seus arredores dos anos de a: 1957; b: 1977; c: 1994; d: 1998; e: 2001 e f: 2002 (IPUF, 1957, 1977, 1994, 1998, 2001, 2002). 
Esse estudo mostrou que a quantidade de água da lagoa não sofreu alteração ao longo dos anos somente em decorrência do assoreamento (provocado por uso descontrolado de águas subterrâneas, construção de canal de drenagem na direção Sul, aterros ao redor da lagoa, eutrofização artificial), mas também, devido às diferenças climáticas sazonais e anuais nos índices de precipitação. Tal constatação foi feita quando se percebeu um aumento na lâmina da água de 1957 para 1977. Isso não era previsto, levando em conta os processos decorrentes de interferências humanas expostos acima e que normalmente contribuem para a redução da água. Nos anos subsequentes, esses processos de interferência na lagoa se agravaram em decorrência do aumento de residências, o que diminuiu o espelho da água, favorecendo o crescimento de macrófitas aquáticas.

Algumas fotos, obtidas com três moradores dos arredores da Lagoa da Chica, datam das décadas de 1980 e 1990 . As fotos de 1985 mostram que havia uma lâmina de água ampla na lagoa e pouca quantidade de taboa. Através das fotos de 1993 e 1994, pode-se observar que, ao redor da lagoa, aumentou a quantidade de taboa e havia muito lixo. A foto de 1998 mostra que ainda era viável andar de barco na Lagoa da Chica, embora a taboa continuasse presente, e que existia um parquinho construído pelos moradores. Antes das chuvas intensas ocorridas no segundo semestre de 2005 a lagoa estava sem água. As fotos de outubro e de novembro de 2005 permitem visualizar que mesmo após as chuvas a lâmina da água estava reduzida e havia muita taboa.

Atualmente, a Lagoa da Chica está sem lâmina de água e quase totalmente invadida por taboa e peri, além de apresentar muito lixo e gramíneas com crescimento não controlado, em seus arredores.

\section{Atividades com os alunos}

No trabalho desenvolvido na escola, já no primeiro contato com as crianças, pode-se perceber que muitas, aproximadamente metade de cada turma, não conheciam a lagoa, apesar de ela se localizar a pouco mais de $1 \mathrm{~km}$ da escola.

Apesar de os alunos desconhecerem a lagoa, pode-se perceber que eles já estavam cientes do poder de modificação do homem sobre a natureza, pois muitos dos temas abordados eles já haviam ouvido.

$\mathrm{Na}$ primeira aula, quando divididos em equipes, somente começaram a discutir os assuntos propostos depois de uma fala sobre a importância dos temas em seu dia-a-dia. A equipe que trabalhou com as fotos aéreas ficou muito entusiasmada; os alunos tentavam 
localizar suas casas e os lugares conhecidos nas imagens. Os outros grupos não se envolveram com a mesma intensidade na atividade, supõe-se que isso se deva à falta de estímulo concreto como a fotografia.

O resultado final da primeira aula foi observado na segunda, quando os alunos produziram textos. Neles foram registradas opiniões muito interessantes, conforme alguns trechos destas descritos abaixo:

Na foto de 1957 a lagoa da chica tinha um pouco de vegetação no meio dela, em 1977 a lagoa da chica tem mais vegetação, a vegetação cresce e diminui porque a água fica transbordando. Na foto de 94 já tem um pouco menos de vegetação mas tem um pouco mais de areia, em 98 tem mais vegetação do que em 94, na foto de 2001 já tem um pouco vegetação na lagoa da chica e em 2002 tem mais vegetação porque baixou o niveu de água na lagoa da chica. (Aluno da $5^{\mathrm{a}}$. série)

O aluno acima foi o único a elaborar uma descrição dos elementos da paisagem ao longo do tempo que não correspondeu com o observado. Entretanto, para todos os demais as fotos aéreas possibilitaram que eles fizessem uma interpretação adequada sobre o processo de evolução da lagoa.

A lagoa da Chica a muitos anos atrás tinha peixes, não era poluída, tinha uma vegetação nativa, dizem que tinha até jacaré, mais hoje em dia não existe mais nada disso a lagoa foi tomada pelo mato por causa do auto nível de poluição, começaram a jogar lixo, esgotos desembocavam nela e assim ela ficou no estado que esta hoje.

A lagoa pequena também esta poluída mais não tanto como a lagoa da Chica, a lagoa pequena é muito vizitada e antigamente a água uzada nas coisas para beber com um sistema de tratamento mais por causa da poluição o sistema de tratamento foi desativado, na lagoa pequena ainda existem peixes e da para mergulhar, no verão tem alguns turistas que acampam e ficam muitos dias. Mas enfelizmente ela também esta ficando que nem a lagoa da Chica. (Aluno da $8^{a}$. Série)

O aluno percebeu que o mesmo processo ocorrido na Lagoa da Chica está acontecendo em outra lagoa de mesmas características geomorfológicas.

A lagoa da chica e a lagoa da conceição são muitas diferenças, pois a lagoa da chica não tem peixe o tamanho é pequeno e água é doce e não tem embarcação, porque é rasa. E já a lagoa da conceição tem peixe de tamanho grande de água salobra, tem embarcações e é funda. A lagoa da chica com um tempo vai acabar, deixar de existir, a lagoa se ninguém cuidar é capaz de chegar como a chica (acabar). (Aluna da $8^{\mathrm{a}}$. série)

Este aluno ressalta que até mesmo com a Lagoa da Conceição, que é muito maior, pode acontecer o que ocorreu com a Lagoa da Chica. 
A poluição é cada vez mais freqüente em todo o lugar. E praticamente a culpa de toda dessa poluição é do homem, e do nosso governo, pois as cidades estão crescendo sem estrutura para isso quanto mais a população cresce mais almenta o número de lixo. Em muitas casas (na maioria delas) as fossas (as sujeiras delas) vão direto para o solo, e isso acaba poluindo o lençol freático, e assim então muitas das lagoas e rios que conhecemos ficam poluídos, como é o caso da lagoa da Chica. Se as pessoas comesasem a separar seus lixos, não jogalos na rua, e nos mares, lagos e rios, se o governo fizesse um tratamento de esgoto (que a sujeira das fossas não fossem direto para o solo) já seria uma grande coisa. (Aluna da $8^{\mathrm{a}}$. série)

A poluição é um assunto cada vez mais preocupante no nosso mundo, por isso devemos tomar uma iniciativa começando pelo lugar em que vivemos como nossa casa ou até mesmo nosso bairro.

Eu sou moradora do Campeche a cinco anos e desde que cheguei tenho visto aos poucos o crescimento do lixo nas ruas, os moradores da região parecem não se importar com isso e continuam a jogar o lixo nas ruas sem pensar nas conseqüências que irão causar no futuro. Outro assunto preocupante é o número de animais abandonados que sem um lar fazem suas fezes nas ruas aumentando o número de ratos, baratas, etc...

Com crescimento da população começou um outro tipo de poluição, a poluição SONORA e também a poluição VISUAL. (Aluna da $5^{\mathrm{a}}$. série)

Uma das alunas destaca bem a responsabilidade conjunta do cidadão e do governo em relação à poluição. Ela aborda os tipos de poluição mais comumente discutidos como lixo, esgoto, poluição da água, etc. Já a outra menciona tipos menos citados de poluição, como a sonora e a visual.

A dinâmica da teia de barbante, realizada no final do segundo encontro, fez com que os alunos percebessem as interações entre os elementos naturais e sociais e puderam novamente refletir sobre as interferências dos seres humanos nos ecossistemas aquáticos da Ilha de Santa Catarina.

Na saída para a Lagoa da Chica, terceiro encontro, os alunos das duas turmas que não a conheciam não pareceram muito interessados, talvez porque esperavam encontrar um ambiente com mais água. No início todos estavam reunidos na mesa localizada no canto da lagoa. Porém, a entrega das perguntas, às quais cada equipe deveria responder, despertou neles a observação do ambiente. A partir daí, espalharam-se e percorreram a área.

Após a observação do local alguns registros foram realizados. As perguntas (destacadas em negrito) e algumas respostas (colocadas entre aspas) seguem abaixo.

\section{Por que você acha que a vegetação tomou conta da lagoa?}


"Porque as ponteiras foram retirando água da Lagoa e a Lagoa foi secando e a vegetação tomou conta da Lagoa. A vegetação também tomou conta da Lagoa porque abriram um cano e a água foi desaparecendo pouco a pouco.” Alunos da 8a . série

\section{Você vê se há algum tipo de vegetação dominante? Por que?}

“Taboa e outros matos. Porque tem muitos minerais.” Alunos da 8 a série

Que animais você viu na lagoa? O que você acha que poderia ter? Qual a importância da lagoa para esses animais?

"Boi, quero-quero (passarinho), formiga. Poderia ter: peixes, jacaré, sapo, grilo, borboleta, abelha, zangão. A importância da lagoa para esses animais é o seu habitat, algumas plantas que só nascem em ambiente úmidos servindo de alimentos para os animais existentes na lagoa da Chica.” Alunos da $8^{\mathrm{a}}$. série

Você sabe por que a água da lagoa desapareceu? Você já viu a lagoa com água?

"Porque os esgotos trazem nutrientes para as plantas. As que morrem continuam no ambiente assoriando o ambiente.

Os aterros, lixos depositados no ambiente, grandes quantidades de possos artesianos tiram água do subsolo. Nunca vimos água na lagoa. ” Alunos da $8^{\mathrm{a}}$ série

\section{Que tipos de lixo você encontra nos arredores da lagoa?}

“Pano, papelão, potes de vidro, plástico, papel, alumínio, pilha, vela de carro, algodão, pneu, ferro, porcelana." Alunos da $5^{\mathrm{a}}$ série

\section{Você acha que a água da lagoa é doce ou salgada?}

“Água doce, porque ela é abastecida pelo lençol freático e pela chuva.” Alunos da $5^{\mathrm{a}}$ série

$\mathrm{Na}$ atividade com argila, os alunos deviam representar em suas maquetes o que imaginavam do passado, do presente ou para o futuro da lagoa (Figura 2). A produção de maquetes em argila foi um ótimo recurso didático, pois possibilitou ao aluno manifestar sua criatividade em formas de três dimensões, dando realmente a ideia do concreto.

O passado foi representado com muito verde ao redor da lagoa e muita água em seu interior, com animais como peixes e jacarés.

Para o presente, quase todas as equipes construíram uma lagoa sem água, com pouca diversidade vegetal, ausência de animais aquáticos (aparecendo somente cachorros) e esgotos fluindo para a lagoa. Isso é resultado da saída de campo feita no $3^{\circ}$ encontro.

Para o futuro, as equipes foram otimistas, pois viram a lagoa voltar a ser o que era, ou ao menos, se transformar em um espaço de lazer bem cuidado. 
EXTENSIO: Revista Eletrônica de Extensão

Ano 6 • n. 7 • Julho de 2009 • ISSN: 1807-0221

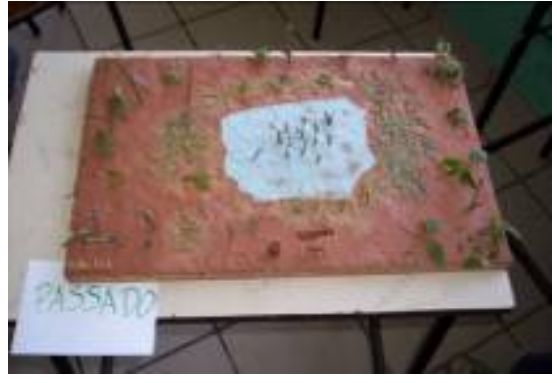

a

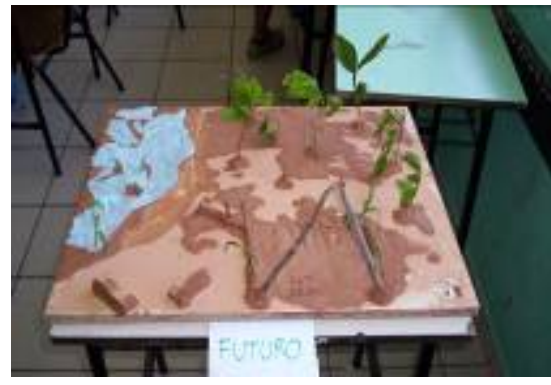

C

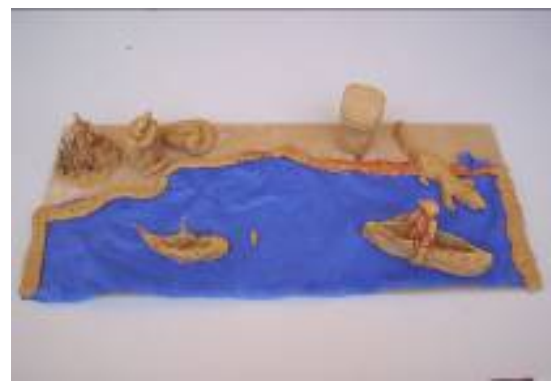

e

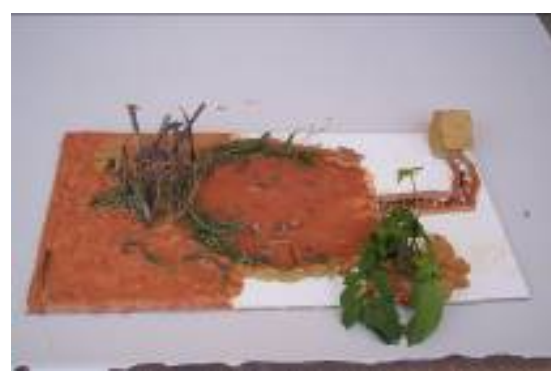

g

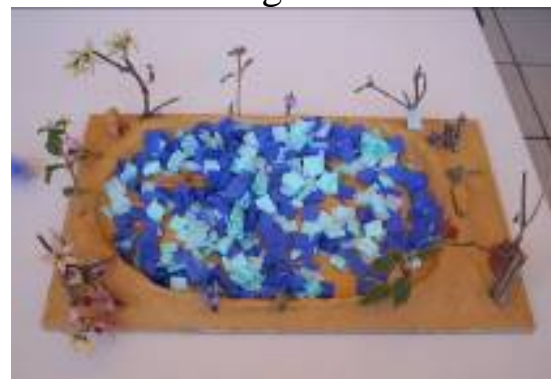

i

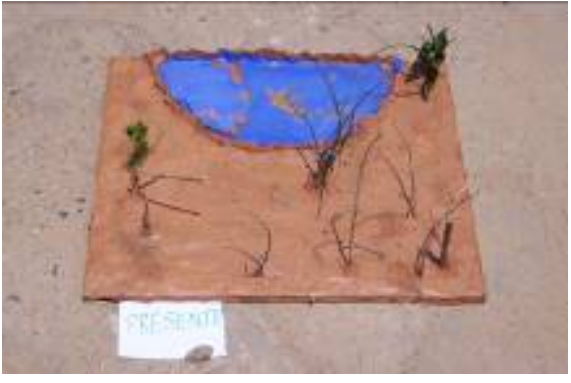

b

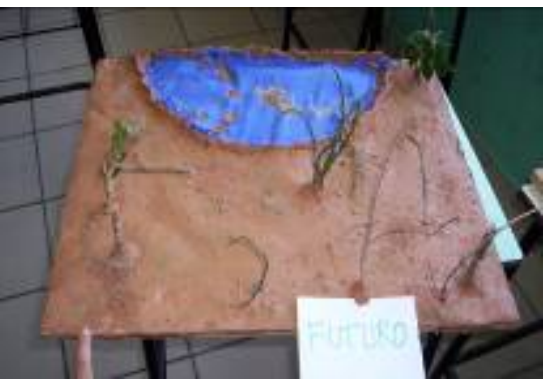

d

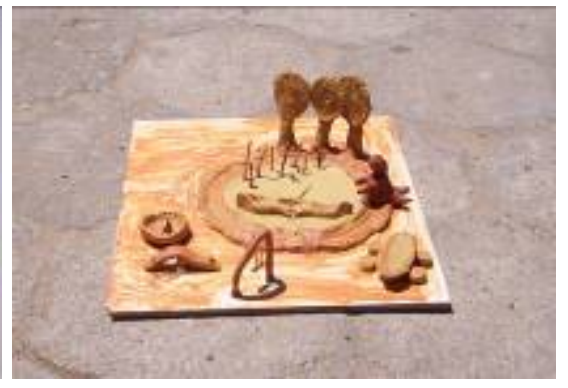

$\mathrm{f}$

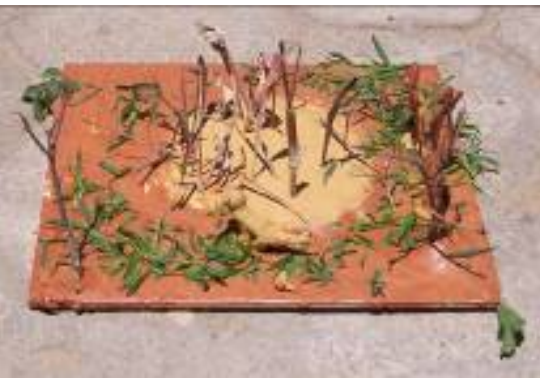

h

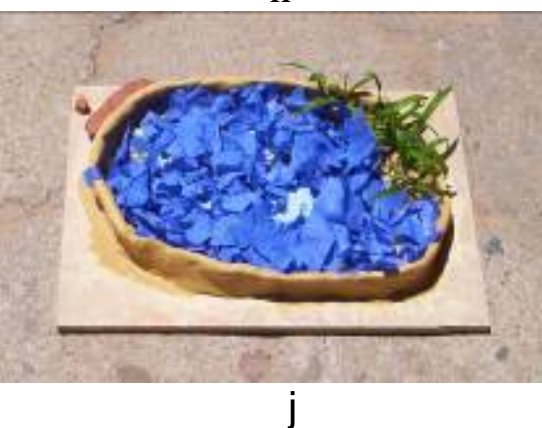

Figura 2: Maquetes construídas com os alunos da $5^{\mathrm{a}}$ (a,b,c,d) e $8^{\mathrm{a}}$ (e,f,g,h,i,j) séries da Escola Municipal Brigadeiro Eduardo Gomes, representando a Lagoa da Chica no: a:passado; b: presente; c,d: futuro; e,f: passado; g,h: presente e i,j: futuro. 
A representação humana pelos alunos foi diferente nos três períodos históricos trabalhados. O presente e o passado foram representados com humanos ao redor da lagoa; a diferença está no fato que no presente eles apareceram como elemento impactante, e no passado como elemento contemplativo. Isto mostra que as crianças têm uma visão negativa da interação do homem com o meio ambiente atualmente. A presença humana no futuro foi tratada através de indícios, e não do ser humano propriamente dito. Apareceram apenas artefatos de produção humana como bancos e parquinhos.

As ideias de ações para o futuro da lagoa, apresentadas pelos alunos no último encontro, refletem um pouco o interesse pessoal de cada um. Seguem abaixo alguns dos pensamentos transcritos por eles, e que, apesar das dificuldades, mostram o interesse em transformar a lagoa em um espaço de lazer:

Na minha opinião o governo ou a prefeitura ou até os dois juntos deviam instalar um sistema de tratamento na lagoa da Chica e tentar novamente, tirando o mato, tratando a água, cercando-a para que não jogassem mais lixo e assim tentando diminuir a poluição. Poderiam separar um espaço pequeno de terra ao lado da lagoa e botarem uma pequena pracinha para que no verão pessoas fiquem ali com a família em dias ensolarados e possam se banhar na lagoa e depois ficar na sombra sentados em banquinhos ou até fazendo churrasco e almoçar ali. (Aluno da $8^{\mathrm{a}}$ série)

A minha opinião na sociedade não vale nada se eu estiver sozinha , eu simplesmente acho que a sociedade deveria se unir e fazer um mutirão para limpar e fazer uma pracinha de recreação para as pessoas nos finais de tarde e nos feriados poder ter um lugar para ir e se distrair. (Aluna da $8^{\mathrm{a}}$ série)

As pessoas deveriam limpar a lagoa e fazer um parquinho para as crianças brincarem e botar uma cerca para ninguém destruir.

Pois muitas pessoas jogam lixo na lagoa .

E destroem nossa lagoa põem fogo e se fosse cercada ninguém ia fazer isso. (Aluna da $8^{\mathrm{a}}$ série)

Eu acho que devemos privatizar a lagoa para alguém que queira fazer um parque ou uma área de lazer mas que mecha com água para diversão da população. (Aluno da $8^{\mathrm{a}}$ série)

Bem, nós achamos que a lagoa da Chica deveria ser mais preservada, mas não sabemos como fazer isto, pois dependendo do clima, se está seco ou chuvoso, pois tendo chuva a lagoa não fica tão seca.

Pensamos também em destruir ela, mas não tem graça, pois faz parte da história do Campeche. Ainda á gerações que não sabem da existência da lagoa, isso é um forte motivo para ela continuar existindo, por isso achamos que ela deveria ser mais preservada, para até mesmo os turistas conhecer um pouco da historia do Campeche. (Alunas da $8^{\mathrm{a}}$ série)

Diversas sugestões foram levantadas pelos alunos nos textos acima, como retirada do mato, do lixo e a colocação de cerca em volta da lagoa. 
Em alguns registros, transparece a irritação com o tratamento dado à lagoa, especialmente quando mencionam a privatização e a sua destruição. Além disso, deixam claro o sentimento de impotência e a necessidade de união para ocorrer a conservação da lagoa.

As várias atividades desenvolvidas foram importantes, pois alguns alunos não conheciam a Lagoa da Chica, e, com elas, puderam refletir sobre a problemática sócioambiental local e propor soluções para os problemas.

Não era esperado desconhecimento das crianças a respeito deste espaço público. Isto faz refletir sobre a validade do uso da problemática da lagoa para a educação ambiental na escola do bairro. É sugerido que a problemática ambiental deve ser vivida no cotidiano daqueles que participam do projeto de educação ambiental (REIGOTA, 1996), porém, não foi isto o observado no caso dos alunos participantes. A lagoa não fazia parte do cotidiano da grande maioria dos alunos e, assim, percebeu-se que, em alguns momentos, os trabalhos produzidos por eles estavam muito ligados ao caráter de obrigatoriedade, visando obtenção de notas ou vistos, principalmente nas atividades realizadas em sala. Desta forma, constata-se que a escolha de um tema para ser tratado em um projeto de educação ambiental deve mesmo ser feita através de investigações dos interesses dos discentes.

A quantificação do impacto do presente trabalho sobre os alunos é algo extremamente difícil. Conforme menciona Reigota (1996), a educação ambiental se fundamenta basicamente na mudança de mentalidade, comportamento e valores, e a dificuldade de sua avaliação ocorre devido ao seu forte componente subjetivo. Segundo Díaz (2002), as mudanças que a educação ambiental propõe nos envolvidos exigem longo prazo e sua avaliação necessita ser um processo contínuo. Portanto, para observar uma resposta mais concreta dos alunos teria sido necessário um maior convívio com as crianças após o desenvolvimento das atividades.

\section{Considerações Finais}

Esse projeto permitiu utilizar uma problemática sócio-ambiental local para o desenvolvimento de educação ambiental com alunos de uma escola pública. Embora a lagoa esteja localizada no mesmo bairro da escola, muitas crianças não a conheciam o que dificultou a sua participação em certas atividades. Entretanto, as crianças puderam conhecer parte da evolução dos processos ocorridos na lagoa e propuseram ações para o futuro da mesma, mostrando interesse na sua conservação. 
Trabalhos futuros necessitam apresentar um caráter contínuo e de maior duração, o que poderá facilitar a avaliação dos impactos da educação ambiental e gerar maior envolvimento dos participantes.

\section{Referências}

AMORA, A. M. G. A. O lugar do público no Campeche. 1996. 189 f. Dissertação (Mestrado em Geografia) - Centro de Filosofia e Ciências Humanas, Universidade Federal de Santa Catarina, Florianópolis, 2001.

BARBOSA, Tereza Cristina Pereira. Adote a Lagoa Pequena: relatório final do projeto de extensão da UFSC (mimeografado) Florianópolis: 1999, 74 p., 19 anexos.

BARBOSA, Tereza Cristina Pereira. Ecolagoa: um breve documento sobre a ecologia da bacia hidrográfica da Lagoa da Conceição. Florianópolis: Agnus, 2003, 86 p.

CARVALHO, Isabel Cristina de Moura. Educação ambiental: a formação do sujeito ecológico. São Paulo: Cortez, 2004, 256 p.

CECCA. Centro de Estudos, Cultura e Cidadania. Unidades de conservação e áreas protegidas da Ilha de Santa Catarina: caracterização e legislação. Florianópolis: Insular, 1997, 160 p.

DÍAZ, Alberto Pardo. Educação ambiental como projeto. 2. ed. Porto Alegre: Artmed, 2002, 167 p.

FAZENDA, Ivani Catarina Arantes. Interdisciplinaridade: definição, projeto, pesquisa. In: FAZENDA, Ivani Catarina Arantes (Coord.) Práticas interdisciplinares na escola. 3. ed. São Paulo: Cortez, 1996, p. 19-25.

FLORAM. Fundação Municipal do Meio Ambiente. Áreas de preservação. Florianópolis. [s.d.]. Disponível em: http://www.pmf.sc.gov.br/portal/meioambiente/. Acesso em: 30 mar. 2006.

GUIMARÃES, Mauro. A dimensão ambiental na educação. Campinas: Papirus, 1995, 107 p.

GUIMARÃES, Mauro. Educação ambiental. Duque de Caxias: UNIGRANRIO, 2000, 61 p. 
IPUF. Instituto de Planejamento Urbano de Florianópolis. Fotografia aérea da planície do Campeche. 1957.

IPUF. Instituto de Planejamento Urbano de Florianópolis. Fotografia aérea da planície do Campeche. 1977.

IPUF. Instituto de Planejamento Urbano de Florianópolis. Fotografia aérea da planície do Campeche. 1994.

IPUF. Instituto de Planejamento Urbano de Florianópolis. Fotografia aérea da planície do Campeche. 1998.

IPUF. Instituto de Planejamento Urbano de Florianópolis. Fotografia aérea da planície do Campeche. 2001.

IPUF. Instituto de Planejamento Urbano de Florianópolis. Fotografia aérea da planície do Campeche. 2002.

MCQV. Movimento Campeche Qualidade de Vida. Plano Comunitário para a Planície do Campeche. Florianópolis, 2000. Disponível em:

http://www.campeche.org.br/MCQV/index.php?option=com_wrapper\&Itemid=34. Acesso em: 30 março 2006.

REIGOTA, Marcos. O que é educação ambiental. São Paulo: Brasiliense, 1996, 62 p. 